\title{
A RETRATAÇÃO DO VETO
}

\section{Carlos Eduardo Thompson Flores Lenz ${ }^{1}$}

\begin{abstract}
"The President can not recall a veto though it is signed under a misapprehension...”

David Watson, The Constitution of the United States, Chicago, 1910, v. I, p. 375.
\end{abstract}

A Constituição Federal de 1988, seguindo a tradição constitucional desde a Carta Imperial de 1824, mantém o instituto do veto, isto é, autoriza a Lei Maior que o Chefe do Poder Executivo recuse sanção a projeto de lei já aprovado pelo Legislativo, dessa forma impedindo a sua transformação em lei (art. 66, § $1^{\circ}$, da CF/88).

A propósito, diz Harold Laski, ao examinar a experiência constitucional norte-americana, verbis:

The President has also the veto power, in its various forms, as a method of influence. No one now accepts the view of Washington that a Bill should be vetoed only upon the ground of its probable unconstitutionality. "If anything has been established by actual practice," wrote President Taft, "it is that the President, in signing a Bill, or returning it unsigned, must consider the expediency and wisdom of the Bill, as one engaged in legislation and responsible for it. The Constitution used the word 'approve,' and it would be a narrow interpretation to contract this into a mere decision as to legal validity.” This is the generally accepted view ... On the whole, it cannot be said that the power is a

1 Desembargador Federal do TRF da $4^{\mathrm{a}}$ Região. 
great one, or that it has been widely used; and Congress can always overrule the President by a two-thirds majority of the members who constitute a quorum in either House. Eight Presidents (seven of them in office before the Civil War) did not exercise their veto power at all. Of the earlier Presidents, Wahington exercised it twice, Madison on six occasions, and Monroe once. Jackson vetoed twelve measures, and Tyler nine. In the post-Civil War period, Grant vetoed forty-three Bills, Roosevelt forty, and Woodrow Wilson twenty-six. Cleveland vetoed no less than 358 measures; but the vast majority of them were private pensions Bills of an indefensible character. The passage of a Bill over the President's veto is infrequent. $^{2}$

O ponto nodal da questão está em saber se a Constituição admite a possibilidade de retratação de um veto pelo titular do Poder Executivo.
A doutrina, em expressiva maioria, responde pela negativa, concluindo que o uso do veto não permite arrependimento e, uma vez lançado, é irretratável.

Pontes de Miranda, com insuperável clareza, expõe esse princípio de Direito Constitucional com estas palavras, verbis:

Vetado o projeto de lei, não pode o Poder Legislativo resolver corrigilo e submetê-lo a novas discussões. A fortiori, pedir que o Presidente da República lho devolva, para que, antes da sanção, se emende. Os trâmites da elaboração das leis são irreversíveis. Também o Presidente da República que exerceu o direito de vetar, não pode penitenciar-se, e revogar, ou modificar o veto. Se vetou totalmente o projeto de lei, não lhe é permitido passar ao veto parcial. Se só parcialmente o vetou, não se lhe concede vetá-lo duas vezes, em parte, ou mais de uma vez no todo. ${ }^{3}$

2 LASKI, Harold J. The American Presidency - An Interpretation. Third Impression, George Allen \& Unwin Ltd, London, 1952, p. 147-8. Nesse sentido, ainda, as obras de Thomas C. Marks e John F. Cooper, State Constitutional Law, West Publishing Co., St. Paul, Minn., 1988, p. 57-61, e Jerome A. Barron e C. Thomas Dienes, Constitutional Law, 7 th Edition, West, St. Paul, Minn., 2009, p. 168-76.

3 MIRANDA, Pontes de. Comentários à Constituição de 1967 com a Emenda n $n^{\circ} 1 / 69$, 2. ed., Editora Revista dos Tribunais, São Paulo, 1970, t. III, p. 322. Nesse entendimento, ainda, os seguintes autores: Carlos Maximiliano, Comentários à Constituição Brasileira, 4. edição, Livraria Editora Freitas Bastos, Rio, 1948, v. II, p. 178, n 364; Aurelino Leal, Theoria e Prática da Constituição Federal Brasileira, Parte Primeira, F. Briguiet e Cia. Editores, Rio de Janeiro, 1925, p. 851; Ernesto Rodrigues, O Veto no Brasil, 1. edição, Forense, Rio de Janeiro, 1981, p. 52; José Afonso da Silva, Processo Constitucional de Formação das Leis, 2. ed., $2^{\mathrm{a}}$ tiragem, Malheiros Editores, p. 227-8, n. 17; José Celso de Melo F ${ }^{\circ}$, Constituição Federal Anotada, 2. ed. ampliada, Saraiva, 1986, p. 224. 
Em tal sentido, anotou o consagrado Professor Mario Casasanta, em sua clássica tese de concurso "O Poder de Veto", verbis:

Pergunta-se se, tendo devolvido o projeto, com os motivos do veto, pode o presidente, ainda dentro dos dez dias úteis, ou mudar de resolução, não o vetando, ou, tendo-o vetado parcialmente, querer vetá-lo em outra parte.

Paulo de Lacerda responde negativamente às duas hipóteses. O veto é ato único e irretratável. O presidente pode usá-lo só uma vez, e, uma vez usado, não pode arrepender-se. Tem de passar pelos trâmites que a constituição lhe determina.

$O$ veto não tem a mesma sorte que a sanção: uma vez posta a assinatura no projeto, torna-se lei, ainda que se não devolva ao legislativo, ao passo que o veto se malogra, com a não devolução, dentro dos dez dias úteis.

Watson, Constitution of the Unites States, I, p. 363, dá-nos conta de uma decisão nesse sentido. Como um governador sancionasse um projeto e sobreviesse o encerramento das sessões legislativas, o presidente do senado, que veio a substituí-lo, encontrou o projeto e opôs-lhe veto, não obstante a sanção. Decidiu-se que a sanção do governador fôra definitiva, sendo nula, por isso mesmo, a ação do segundo.

Quanto à irretratabilidade, parece não haver dúvida.

Ela decorre do texto, que não prevê senão uma remessa do projeto do legislativo para o executivo e uma devolução do executivo para o legislativo.

É o que ocorre nos Estados Unidos.

Woodburn, apud Aurelino Leal, Teoria e Prática, p. 851:

O presidente Grant, em 15 de agosto de 1876 , vetou o projeto relativo à venda de terras de índios, enviando sua mensagem de veto ao senado. Antes, porém, que esta câmara tivesse tomado conhecimento dela, recebeu do presidente outra dizendo que o veto fôra prematuro e pedindo que o projeto lhe fosse devolvido para ser assinado. Travou-se debate para saber se o presidente podia reconsiderar o veto. Foi geralmente sustentado que ele não tem tal poder e que o único efeito da segunda mensagem era induzir a aprovação da mensagem sobre o veto.

A irretratabilidade decorre do texto, porque não a prevê, mas essa unicidade pode ser posta em dúvida, com alguma razão. ${ }^{4}$

Na mesma linha, sinalou Paulo de Lacerda, verbis:

482 - De resto, o poder de vetar é indelegável, e o veto irretractavel, tal como o de sanccionar e a sancção. Trata-se de attribuição pessoal do Presidente da Republica, e que ele pode usar uma unica vez a cada projecto; mas que, em usando-a, esgota essa mesma respectiva attribuição. É o que se verifica nos 
preceitos constitucionaes acerca do instituto. $^{5}$

Ao dissertar acerca da matéria, à vista do sistema constitucional americano, escreveu James Woodburn, verbis:

President Grant on August 15, 1876, vetoed a bill for the sale of certain Indian lands. He sent his veto message to the Senate, but before that body had acted upon it a message was received from the President, saying that his veto was premature, and he requested that the bill be returned to him that he might sign it. A discussion arose as to whether the President could recall a veto message. It was generally held that the President had no such power, and the only effect of the second message was to induce the passage of the bill over the veto. ${ }^{6}$

No mesmo itinerário de pensamento, conclui Watson, verbis:

The President can not recall a veto though it is signed under a misapprehension and it was held by the Virginia Court of Appeals in Wolfe v. McCaull, that the legislature could not recall a bill which had been sent to the governor for his approval. ${ }^{7}$
O Supremo Tribunal Federal, ao julgar a Representação n ${ }^{\circ}$ 432-DF, em 22 de janeiro de 1960, sendo relator o Ministro Ary Franco, teve a oportunidade de se pronunciar a respeito de retratação do veto.

O acórdão possui a seguinte ementa, verbis:

O poder de veto, se usado pelo executor, não pode ser retratado. ${ }^{8}$

Em seu voto, disse o relator, o eminente e saudoso Ministro Ary Franco, verbis:

Sr. Presidente, como viu o Tribunal, do relatório e das exposições feitas pelo Dr. Procurador-Geral da República e pelo ilustre advogado que ocupou a tribuna, depois de vetado um projeto de lei, o governador do Estado de Pernambuco se dirigiu a Assembleia Legislativa, pedindolhe que devolvesse o mesmo, dizendo que vira estar errado e não ser de subsistir o veto. Daí a sanção da lei votada pelo Legislativo estadual. Como disse o ilustre advogado, o que o governador fez foi vetar e desvetar. O problema é saber se é lícito ao governador, depois da devolução à Assembleia Legislativa do projeto vetado, retratar-se. O ilustre advoga-

5 LACERDA, Paulo de. Princípios de Direito Constitucional Brasileiro, v. 2, p. 292, n. 482.

6 WOODBURN, James A. The American Republic and its Government, second, revised, edition, G. P. Putnam’s Sons, New York and London, 1916, p. 156.

7 WATSON, David K. The Constitution of the United States - Its History Application and Construction, Callaghan \& Company, Chicago, 1910, v. I, p. 375.

8 RTJ 13/89. 
do, a meu ver, não deixou pedra sobre pedra. Trouxe a atenção do Tribunal opiniões de todos os tratadistas na matéria, inclusive comentadores nacionais, a começar por Paulo Lacerda, na vigência da Constituição de 1891, e o seu excelente comentário sobre a Constituição, particularmente, os ensinamentos a respeito de Mario Casasanta, na sua tese de concurso “O Poder de veto", que tenho em mãos, em que se diz, incisivamente “ - o presidente pode usá-lo só uma única vez e, uma vez usado, não pode arrepender-se. Tem de passar pelos trâmites que a Constituição lhe determina”. Páginas adiante, ele timbra em mostrar que o que perfaz o veto é a devolução. Ora, desde que o Governador havia vetado a lei, a solução estaria naquilo que por vezes, é usado pelo Presidente da República e foi osto em relevo pelo ilustre advogado, com muita oportunidade: é aconselhar o Congresso a rejeitar o veto (no caso, seria a Assembleia Legislativa). Longe do entendimento que dá o Dr. Procurador-Geral da República ao assunto, em penso que o Governador bem se houve nesta representação, porque atenta contra a independência e harmonia dos poderes e torna inconstitucional a lei. ${ }^{9}$

E o Ministro Nelson Hungria, ao proferir o seu voto, assinalou, verbis:

Sr. Presidente, também entendo que, se admite a possibilidade da retratação de um veto, a lógica nos levaria à conclusão de que o Governador poderia, igualmente, revogar a sanção, desde que ainda não expirado o prazo que tinha, para esta.

É verdade que houve um acordo, uma entente entre a Assembleia Legislativa e o Governador, mas, quando estão em jogo interesse público e um preceito constitucional, em face do qual não é possível que dois Poderes se entendam, para que um interfira na órbita do outro, não pode haver essa transação ou acomodação recíproca. A Assembleia Legislativa, ao receber o veto do Governador, não podia, a seguir, renunciar o direito de apreciálo, para aceitá-lo ou rejeitá-lo.

Assim, estou de acordo com o voto do Sr. Ministro Relator. ${ }^{10}$

Nessa conformidade, à vista dos princípios sucintamente expostos, da communis opinio doctorum, da doutrina estabelecida, generalizada e definitivamente consagrada (Bewaehrte Lehre), aceita por mestres de consolidado prestígio, é lícito concluir que o poder de veto, previsto no artigo 66, $\S 1^{\circ}$, da Carta Política, somente pode ser utilizado pelo Chefe do Poder Executivo uma única vez e, uma vez usado, é irretratável.

Para finalizar, seja-me permitido colacionar o depoimento do Presidente Theodore Roosevelt acerca da importância e da gravidade da utilização do "veto power", verbis: 
It is customary to speak of the framers of our Constitution as having separated the judicial, the legislative and the executive functions of the government. The separation, however, is not in all respects sharply defined. The President has certainly most important legislative functions, and the upper branch of the national legislature shares with the President one of the most important of his executive functions; that is, the President can either sign or veto the bills passed by Congress, while, on the other hand, the Senate confirms or rejects his nominations. Of course the President can not initiate legislation, although he can recommend it. But unless two-thirds of Congress in both branches are hostile to him, he can stop any measure from becoming a law. This power is varyingly used by different Presidents, but it always exists, and must always be reckoned with by Congress. ${ }^{11}$

Nessa mesma linha, ainda, o pensamento do Presidente Calvin Coolidge, verbis:

When I took office I gave an oath to support the Constitution of the Unites States. [...] My oath was not to take a chance on the Constitution; it was to support it. When the proponents of this measure do not intend to jeopardize their safety by acting under it, why should I jeopardize my oath by approving it?
We have had too much legislating by clamor, by tumult, by pressure. Representative government ceases when outside influence of any kind is substituted for the judgment of the representative. This does not mean that the opinion of constituents is to be ignored. It is to be weighed most carefully... Opinions and instructions do not outmatch the Constitution. Against it they are void. ${ }^{12}$

Com efeito, a instituição do veto pelas constituições visou atender a uma necessidade universalmente sentida, qual seja, a de fornecer meios ao Executivo de expungir dos textos legislativos "pingentes" ou "caudas", ou riders, como os autores americanos os denominam, acrescentados pelos parlamentares no decorrer do processo legislativo.

A gravidade dessa medida, quando utilizada pelo titular do Executivo, pois o coloca na posição de defensor da Carta Magna, exercendo um verdadeiro controle preventivo para resguardá-la de qualquer violação ao seu texto, resultante da entrada em vigor de uma lei inconstitucional, implica, uma vez aposto o veto, a impossibilidade de sua posterior retratação.

Verba clara non admittunt interpretationem, neque voluntas conjecturam.

11 Presidential Addresses and State Papers of Theodore Roosevelt - Part one, P. F. Collier \& Son Publishers, New York, p. 2-3.

12 COOLIDGE, Calvin. The Price of Freedom - Speeches and Addresses. New York; London: Charles Scribner's Sons, 1924, p. 406-7. 